\title{
The Acid/Base Chemistry of Montmorillonite
}

\author{
By Hans Wanner ${ }^{1}$, Yngve Albinsson ${ }^{2}$, Ola Karnland ${ }^{3}$, Erich Wieland ${ }^{1}$, Paul Wersin ${ }^{1}$ and Laurent Charlet ${ }^{4}$ \\ ${ }^{1}$ MBT Umwelttechnik AG, Zürich, Switzerland \\ ${ }^{2}$ Dept. Nuclear Chemistry, Chalmers University of Technology, Gothenburg, Sweden \\ ${ }^{3}$ Clay Technology AB, Lund, Sweden \\ 4 University of Grenoble, Grenoble, France
}

Montmorillonite / Ion exchange / Proton exchange / Surface chemistry / Surface complexation modelling

\begin{abstract}
Alkalimetric and acidimetric titrations of montmorillonite suspensions were performed at ionic strengths varying from 0.005 to $0.5 \mathrm{M}\left(\mathrm{NaNO}_{3}\right)$. Deprotonation of surface hydroxyl groups exposed at the edge sites of montmorillonite platelets causes an overall negative charge in the alkaline $\mathrm{pH}$ range. The PZNPC of the edge sites was determined to be 6.1. In the acidic $\mathrm{pH}$ range, proton exchange at layer sites and protonation of edge sites occur simultaneously. The model parameters were evaluated from experimental data by using the diffuse double layer model. The observations made in these experiments are of key importance for modelling the near-field chemistry and the sorption behaviour of radionuclides.
\end{abstract}

\section{Introduction}

Bentonite clay is envisaged as buffer material in repositories for nuclear waste because of its favourable physical and chemical properties. Among these are the excellent swelling properties, especially of sodium bentonite, the extremely low permeability, and the capability of significantly retarding the migration of most radionuclides. The interaction of deep groundwaters with the clay surface is of importance as it affects the migration of radionuclides. Surface interactions at the clay/water interface, such an ion exchange and protonation/deprotonation reactions, exert control over both pore water and clay composition.

Modelling the interaction processes between bentonite and the constituents of aqueous solutions requires information on the surface properties of the clay fraction consisting of montmorillonite. Quantitatively, the most important interaction process is ion exchange, for which a comparatively large number of data on clays of various origins are available in the literature. However, as suggested in a recent report by Wanner $e t$ al. (1992), a minor type of surface sites, referred to as "edge sites", may have a significant effect on the chemical speciation of the bentonite pore water via interaction with protons, described as proton exchange reactions by Fletcher and Sposito (1989). In fact, such an interaction contributes to the $\mathrm{pH}$ control and can thus influence speciation and the transformation process of Na-montmorillonite to its Ca-form. The experi- mental procedure to examine these interactions, the results and their evaluation are presented in this paper.

\section{Materials and methods}

\subsection{Preparation of Na-montmorillonite}

Na-montmorillonite has been prepared from the commercial bentonite MX-80 available from American Colloid. Bentonite has been pretreated using the procedure given by Sposito et al. (1981) in order to remove carbonate impurities. About $500 \mathrm{~g}$ of the $<2 \mu \mathrm{m}$ fraction was flocculated by adding $8 \mathrm{dm}^{3}$ of a solution containing $0.001 \mathrm{M} \mathrm{HNO}_{3}$ in $1 \mathrm{M} \mathrm{NaNO}$. The supernatant from each sample was decanted after centrifugation. The $\mathrm{pH}$ of the supernatant was measured. The clay was then redispersed in 1.5 times the original volume of the $\mathrm{NaNO}_{3}-\mathrm{HNO}_{3}$ solution and, after shaking for $20 \mathrm{~min}$, again centrifuged. The procedure was repeated until the $\mathrm{pH}$ of the supernatant had dropped to $\mathrm{pH}=3.0$ which was achieved after 5 washings. The clay was then redispersed in $0.1 \mathrm{M}$ $\mathrm{NaNO}_{3}$ until the $\mathrm{pH}$ of the solution had stabilized between $\mathrm{pH} 5.1$ and 5.3. The last two cycles were performed in $0.01 \mathrm{M} \mathrm{NaNO}_{3}$ under argon. Finally, the clay was redispersed in $0.01 \mathrm{M} \mathrm{NaNO}_{3}$ solution and stored in a refrigerator in glass flasks under argon. The BET surface area of the pretreated bentonite was determined to $(31.53 \pm 0.16) \mathrm{m}^{2} / \mathrm{g}$.

\subsection{XRD}

Bentonite material was sampled from the suspension after completing half of the pretreatment procedure and at the end of the pretreatment procedure. The recorded $12.45 \AA d$-spacing, typical for Na-montmorillonite, indicates that no structural transformation had taken place during the pretreatment of bentonite. After completion of the pretreatment procedure no calcite or feldspar related peaks were found, but minor peaks indicating quartz and cristobalite were observed.

\subsection{The cation exchange capacity (CEC) of Na-montmorillonite}

The CEC determinations after the pretreatment procedure resulted in $108 \mathrm{meq} / 100 \mathrm{~g}$. 
Table 1. Overview of the potentiometric titration experiments carried out in the present study

\begin{tabular}{llcc}
\hline Titrations & $I(\mathrm{M})$ & $\begin{array}{c}\text { Number } \\
\text { of titrations }\end{array}$ & $\mathrm{pH}$ range \\
\hline Alkalimetric & $0.005\left(\mathrm{NaNO}_{3}\right)$ & 4 & $7-10.5$ \\
& $0.05\left(\mathrm{NaNO}_{3}\right)$ & 4 & $7-10.5$ \\
& $0.5\left(\mathrm{NaNO}_{3}\right)$ & 4 & $7-10.5$ \\
& $0.5\left(\mathrm{NaCl}^{3}\right)$ & 2 & $7-10.5$ \\
Acidimetric & $0.005\left(\mathrm{NaNO}_{3}\right)$ & 3 & $3.5-7$ \\
& $0.05\left(\mathrm{NaNO}_{3}\right)$ & 2 & $3.5-7$ \\
& $0.5\left(\mathrm{NaNO}_{3}\right)$ & 2 & $3.5-7$ \\
\hline
\end{tabular}

\subsection{Potentiometric titrations}

The interaction of protons and hydroxyl ions with the clay mineral surface was investigated by alkalimetric and acidimetric titrations under exclusion of $\mathrm{CO}_{2}$ from the system. Calibration titrations were carried out and $E^{\circ}$ and $\mathrm{pK}_{\mathrm{w}}$ were determined for each ionic strength.

$100 \mathrm{ml}$ of bentonite suspension $\left(11.25 \mathrm{~g} / \mathrm{dm}^{3}, I=\right.$ $0.0095 \mathrm{M}$ or $11.80 \mathrm{~g} / \mathrm{dm}^{3}, I=0.0185 \mathrm{M}$ ) were added to $125 \mathrm{ml}$ of a $\mathrm{NaNO}_{3}$ solution. Prior to use, the $\mathrm{NaNO}_{3}$ solution was purged with argon for $1 \mathrm{~h}$. The initial concentration of the electrolyte solution was adjusted to give a total concentration of $0.005 \mathrm{M}, 0.05 \mathrm{M}$ or $0.5 \mathrm{M} \mathrm{NaNO}_{3}$ in $225 \mathrm{ml}$ clay suspension. The $\mathrm{pH}$ of the freshly mixed suspension was constant within $30 \mathrm{~min}$ and ranged from 6 to 7.5 depending on the electrolyte concentration. Alkalimetric and acidimetric titrations were performed in separate experiments. E.m.f. readings were recorded after 1,5 and $10 \mathrm{mi}-$ nutes after addition of the titrant. Drifts in the measured potential were between 0.5 and $1 \mathrm{mV}$ in most cases, but in all cases less than $2 \mathrm{mV}$, between the readings after 5 and 10 minutes. In order to investigate a possible effect of chloride on the active montmorillonite surface sites, two alkalimetric titrations were performed using $\mathrm{NaCl}$ as a background electrolyte at $I=0.5 \mathrm{M}$. The surface titrations carried out in the present study are summarized in Table 1.

The results of the surface titrations are shown in Figure 1, where the surface proton concentration, $\Delta\left[\mathrm{H}^{+}\right]$, is plotted against $\mathrm{pH}$. Note that, in this context, $\mathrm{pH}$ refers to $-\log \left[\mathrm{H}^{+}\right]$measured at a given ionic strength. The surface proton concentrations were calculated with the expression

$$
\Delta\left[\mathrm{H}^{+}\right]=\frac{1}{a}\left(\left[\mathrm{H}^{+}\right]_{t}-\left[\mathrm{H}^{+}\right]+\frac{\mathrm{K}_{\mathrm{W}}}{\left[\mathrm{H}^{+}\right]}-C\right)[\mathrm{mol} / \mathrm{g}]
$$

where $\left[\mathrm{H}^{+}\right]_{t}$ total $\mathrm{H}^{+}$concentration $\left[\mathrm{mol} / \mathrm{dm}^{3}\right]$

$\left[\mathrm{H}^{+}\right]$free $\mathrm{H}^{+}$concentration in solution

$\mathrm{K}_{\mathrm{w}}$ ion product of water from calibration titrations

C correction factor for proton consuming side reactions

a initial suspension concentration (solid/ water ratio) $\left[\mathrm{g} / \mathrm{dm}^{3}\right]$
Ionic strengths of the background electrolyte were $I=$ $0.005 \mathrm{M}, 0.05 \mathrm{M}$ and $0.5 \mathrm{M}$. The concentration of surface protons, $\Delta\left[\mathrm{H}^{+}\right]$, was calculated for each data point of an experimental run. Proton balance calculations are based on $\mathrm{pH}$ measurements recorded after an equilibration time of $10 \mathrm{~min}$. Figure 1 shows that the titration of montmorillonite is reproducible for all concentrations of the electrolyte background. The scatter in the experimental data in the strongly alkaline $\mathrm{pH}$ range may be due to variations in the liquid-junction potential. Two distinct branches of the titration curves exist: $\Delta\left[\mathrm{H}^{+}\right]$is positive in the acidic $\mathrm{pH}$ range due to protonation, and negative in the alkaline range due to deprotonation of surface functional groups. Figure 1 further reveals that the degree of deprotonation increases with increasing ionic strength in the alkaline $\mathrm{pH}$ range. This characteristic behaviour of mineral surfaces is typically observed in the case of simple oxides such as $\gamma-\mathrm{Al}_{2} \mathrm{O}_{3}, \mathrm{TiO}_{2}$ or $\mathrm{FeOOH}$, cf. James and Parks (1982). It indicates that deprotonation of surface $\mathrm{OH}$ groups causes the negative charge (i.e. $\Delta\left[\mathrm{H}^{+}\right]<0$ ) on the surface of montmorillonite. Hence the results presented in Figure 1 provide convincing evidence for the fact that the acid/base properties of montmorillonite in the alkaline $\mathrm{pH}$ range are due to ionization of surface $\mathrm{OH}$ groups. From structural arguments we may infer that the reactive $\mathrm{OH}$ groups are likely exposed at the edge face of a montmorillonite platelet.

Figure 1 further reveals that the condition for zero net proton adsorption is achieved in the $\mathrm{pH}$ range 6.5 to 8 depending on the ionic strength of the electrolyte background. Below the PZNPC (point of zero net proton charge) of montmorillonite, the order in the ionic strength dependence of the titration curves in the acidic $\mathrm{pH}$ range is in conflict with experimental observations made for oxides. Figure 1 shows that the concentration of protons adsorbed on the surface, $\Delta\left[\mathrm{H}^{+}\right]$, decreases with increasing ionic strength. If $\mathrm{OH}$ groups were the only surface functional groups accounting for the acid/base properties of montmorillonite in the acidic $\mathrm{pH}$ range, an increase in $\Delta\left[\mathrm{H}^{+}\right]$with increasing ionic strength would be expected. Such a dependence of surface proton concentration upon ionic strength has been reported for simple oxides such as $\gamma-\mathrm{Al}_{2} \mathrm{O}_{3}$, cf. James and Parks (1982). We hence may conclude that the $\mathrm{OH}$ groups of the edge face, which account for experimental observations in the alkaline $\mathrm{pH}$ range, are not the only surface functional groups reacting with protons in the acidic $\mathrm{pH}$ range. The reversal of the ionic strength dependence of $\Delta\left[\mathrm{H}^{+}\right]$in the acidic $\mathrm{pH}$ range can be explained if we assume that protons react with another type of surface sites in an ion-exchange type of reaction. This type of surface functional groups on montmorillonite reacting with protons are structural-charge surface sites (Anderson and Sposito, 1991).

Analyses of $\mathrm{Al}$ and $\mathrm{Si}$ show that proton consumption due to dissolution of the montmorillonite matrix was constant and very small. Al concentrations were around $2 \times 10^{-6} \mathrm{M}$ and $\mathrm{Si}$ concentrations around 


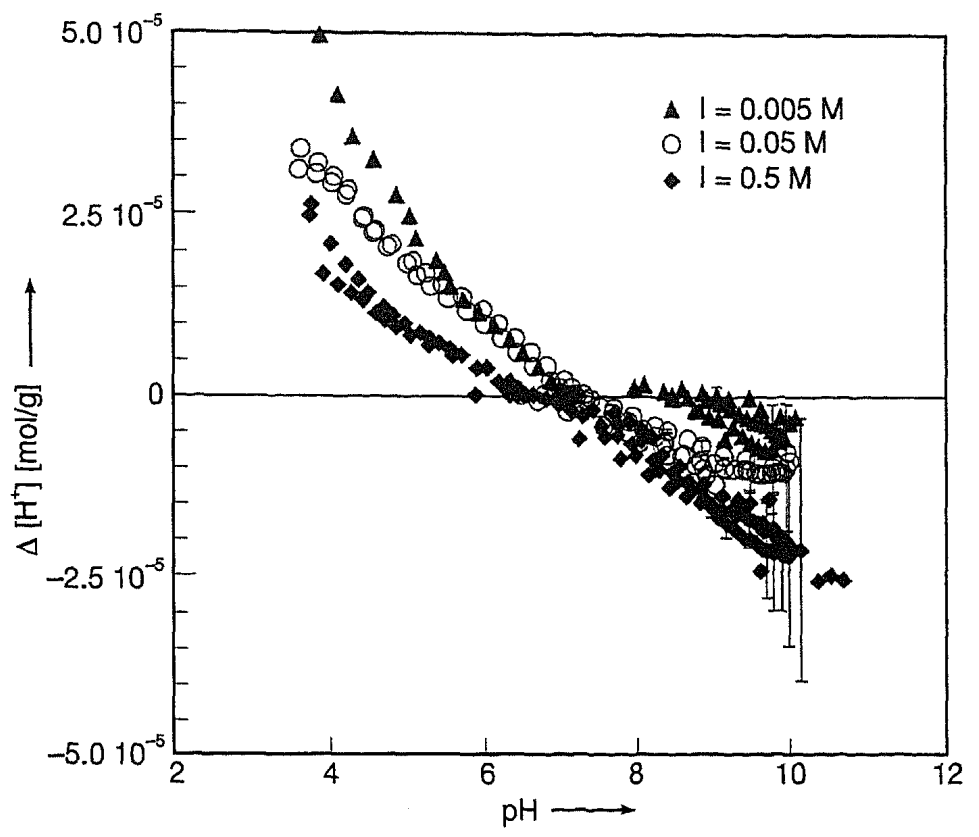

Fig. 1. Titration curves of Na-montmorillonite $\left(5 \mathrm{~g} / \mathrm{dm}^{3}\right)$. Surface proton concentrations, $\Delta\left[\mathrm{H}^{+}\right]$, are plotted as a function of $\mathrm{pH}$ for all titrations performed in the present study, cf. Table 1.

Table 2. Summary of measured surface protolysis reactions and data for montmorillonite as obtained by parameter optimisation in the present study

\begin{tabular}{lcr}
\hline $\begin{array}{l}\text { Surface protolysis } \\
\text { reaction }\end{array}$ & Mass law equation & $\log K$ \\
$\begin{array}{l}\equiv \mathrm{SOH}_{2}^{+} \Leftrightarrow \equiv \mathrm{SOH} \\
+\mathrm{H}^{+}\end{array}$ & $K_{a 1}^{\mathrm{int}}=\frac{\left(\equiv \mathrm{SOH}^{0}\right)\left\{\mathrm{H}^{+}\right\}}{\left(\equiv \mathrm{SOH}_{2}^{+}\right)} \exp \left(-\frac{F \Psi}{R T}\right)$ & -5.4 \\
$\begin{array}{c}\equiv \mathrm{SOH} \Leftrightarrow \equiv \mathrm{SO}^{-} \\
+\mathrm{H}^{+}\end{array}$ & $K_{a 1}^{\mathrm{int}}=\frac{\left(\equiv \mathrm{SO}^{-}\right)\left\{\mathrm{H}^{+}\right\}}{\left(\equiv \mathrm{SOH}^{\circ}\right)} \exp \left(-\frac{F \Psi}{R T}\right)$ & -6.7 \\
$\begin{array}{l}\mathrm{H}^{+}+\mathrm{NaX} \Leftrightarrow \mathrm{HX} \\
+\mathrm{Na}^{+}\end{array}$ & $K_{x}^{\circ}=\frac{\left(x_{\mathrm{HX}}\right)\left(a_{\mathrm{Na}}\right)}{\left(x_{\mathrm{NaX}}\right)\left(a_{\mathrm{H}}\right)}$ & 4.6 \\
$\begin{array}{l}\text { Site density } \\
\text { TOT-SOH: }\end{array}$ & $2.8 \times 10^{-5} \mathrm{~mol} / \mathrm{g}$ & \\
$\begin{array}{l}\text { Site density } \\
\text { TOT-X: }\end{array}$ & $2.2 \times 10^{-5} \mathrm{~mol} / \mathrm{g}$ \\
\hline
\end{tabular}

$1 \times 10^{-4} \mathrm{M}$. The proton balance was corrected, via the parameter $C$ in Eq. (1), according to the hydrolysis constants of these species.

\section{A surface chemical model for montmorillonite}

\subsection{Theoretical background}

Clay minerals contain at least two types of surface functional groups: permanently charged surface functional groups created by ionic substitution within the crystal structure, and variably charged surface functional groups due to ionization of surface $\mathrm{OH}$ groups. The first type of surface sites is due to isomorphic substitution of, e.g., $\mathrm{Al}^{3+}$ for $\mathrm{Si}^{4+}$ within the tetrahedral surface layer causing a permanent charge on the mineral surface. The structural charge is compensated externally by cations interacting with structural-charge surface functional groups. Hereafter, this type of surface sites is denoted as structural-charge surface sites or "layer sites".

In addition to the permanent charge at the layers, the morphological structure of clays also gives rise to a $\mathrm{pH}$-dependent charge on the edge surface. The strongly $\mathrm{pH}$-dependent charge of the edges is due to adsorption of the potential-determining ions $\mathrm{H}^{+}$and $\mathrm{OH}^{-}$as a function of the solution $\mathrm{pH}$. The surface properties of the edge surface of a clay mineral are similar to those found for oxide surfaces (Sposito, 1984; Wieland and Stumm, 1992). Hereafter, this type of surface sites is designated as variable-charge surface sites or "edge sites".

The interaction of protons with layer sites of $\mathrm{Na}$ montmorillonite can be expressed as cation exchange reaction:

$$
\mathrm{H}^{+}+\mathrm{NaX} \Leftrightarrow \mathrm{HX}+\mathrm{Na}^{+} \quad K_{x}
$$

The equilibrium constants, $K_{a 1}$ and $K_{a 2}$, for the protonation and deprotonation reactions of edge sites account for the amphoteric character of the $\mathrm{OH}$ groups, cf. Stumm and Morgan (1981) and Sposito (1984):

$$
\begin{aligned}
& \equiv \mathrm{SOH}_{2}^{+} \Leftrightarrow \equiv \mathrm{SOH}+\mathrm{H}^{+} \quad K_{a 1}^{\mathrm{app}} \\
& \equiv \mathrm{SOH} \quad \Leftrightarrow \equiv \mathrm{SO}^{-}+\mathrm{H}^{+} \quad K_{a 2}^{\mathrm{app}}
\end{aligned}
$$

where $\equiv \mathrm{SOH}$, $\equiv \mathrm{SOH}_{2}^{+}$and $\equiv \mathrm{SO}^{-}$respectively represent the different surface hydroxyl groups of the edge surface, and $K_{a 1}^{\mathrm{app}}$ and $K_{a 2}^{\mathrm{app}}$ are apparent acidity constants.

A number of different surface complexation models have been proposed in the last two decades for adequately modelling the binding of protons, cations and anions onto mineral surfaces. In the present study, we have chosen an improved version of the diffuse double layer model to describe the charge-potential relationship of the interfacial region. The diffuse double 


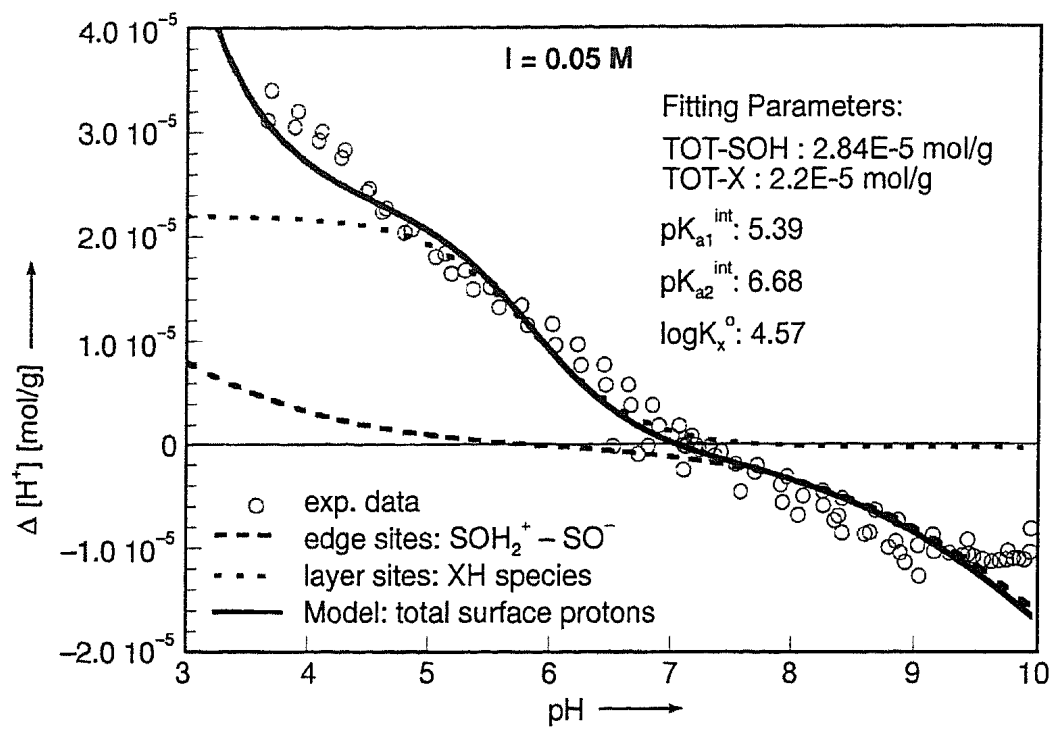

Fig. 2. Titration curve of Na-montmorillonite $\left(I=0.05 \mathrm{~mol} / \mathrm{dm}^{3} \mathrm{NaNO}_{3}\right.$, montmorillonite $\left.=5 \mathrm{~g} / \mathrm{dm}^{3}\right)$. $\Delta\left[\mathrm{H}^{+}\right]$corresponds to the protons bound by the mineral surface. This curve was used for optimizing the model parameters, and it shows also the contributions of edge and layer sites to the total titration curve. The results are presented in Table 2.

layer model (DDLM) originally proposed by Stumm et al. (1970) and Huang and Stumm (1973) has been reviewed and improved recently by Dzombak and Morel (1990). In the DDLM, all ions are adsorbed as coordination complexes within the surface plane, except the dissociated counter ions present in the diffuse layer. We refer to Dzombak and Morel (1990) for a detailed description.

\subsection{Sensitivity estimations}

Uncertainties in $\Delta\left[\mathrm{H}^{+}\right]$, as indicated in Figures 1 and 3 , are estimated on the basis of Eq. (1) with the assumption that the uncertainty in $\left[\mathrm{H}^{+}\right]$dominates over the uncertainties in the other parameters of Eq. (1). Based on the calibration titrations and on the readings of the electrode potentials, the uncertainty in the measured $\mathrm{pH}$ is estimated to be \pm 0.03 . The propagation of errors leads to significant uncertainties at $\mathrm{pH}$ values above 10, cf. Figures 1 and 3.

\subsection{Results and discussion}

The surface chemical model for montmorillonite has been developed based on the following observation: Montmorillonite reveals oxide-like behaviour in the alkaline $\mathrm{pH}$ range as indicated by the sequence of the protonation curves given in Figure 1. In the acid $\mathrm{pH}$ range, however, the acid/base characteristics of montmorillonite show the features of an exchanger phase typically found in clay minerals. The following abbreviations will be used: $\mathrm{SOH}$ for surface $\mathrm{OH}$ groups (edge sites) and $\mathrm{X}$ for the ion exchange sites (layer sites).

The formal treatment of the pertinent protolysis and ion exchange reactions are described by Eqs. (2),
(3) and (4). The corresponding mass law equations are listed in Table 2. Fitting of the model parameters, $K_{a 1}^{\mathrm{int}}$ and $K_{a 2}^{\mathrm{int}}, K_{x}^{\circ}$, TOT-SOH and TOT-X, was performed with the least-square program GRFIT (Ludwig, 1992) which is an extended version of FITEQL (Westall, 1982). The model parameters were optimized for the experimental results determined in a $\mathrm{NaNO}_{3}$ medium with ionic strength $I=0.05 \mathrm{M}$ (Figure 2). The resulting model parameters are summarized in Table 2.

The total number of variable-charge sites, TOT$\mathrm{SOH}$, obtained from the fitting procedure is $2.8 \times 10^{-5}$ $\mathrm{mol} / \mathrm{g}(2.8 \mathrm{meq} / 100 \mathrm{~g})$ corresponding to about $2.6 \%$ of the total CEC (108 meq/100 g). With an estimated specific surface area of the edge face of about $3 \mathrm{~m}^{2} / \mathrm{g}$ (i.e., $9.5 \%$ of the total BET surface area of $\left.(31.53 \pm 0.16) \mathrm{m}^{2} / \mathrm{g}\right)$, the surface site density of $\mathrm{OH}$ groups amounts to 5.7 sites $/ \mathrm{nm}^{2}$, which is within the range of the values typically obtained for oxide minerals ( 2 to 8 sites $/ \mathrm{nm}^{2}$ ). The surface area of the basal planes hence amounts to $28.5 \mathrm{~m}^{2} / \mathrm{g}$, i.e., $90.5 \%$ of the external BET-surface area. Although the validity of our estimate cannot be proved experimentally, the resulting site density is consistent with data reported in the literature.

The intrinsic acidity constants of the protolysis reactions, as defined in Table 2, evaluated from the experiments at $I=0.05 \mathrm{M}$ are $\mathrm{p} K_{a 1}^{\text {int }}=5.4$ and $\mathrm{p} K_{a 2}^{\mathrm{int}}=6.7$. The PZNPC is determined to be 6.1, indicating that the $\mathrm{OH}$ groups exposed at the surface of Na-montmorillonite are stronger acids than aluminol surface sites (PZNPC $=6.6$ to 9.2) but less acidic than silanol groups $(\mathrm{PZNPC}=2.9$ ). From the composition of montmorillonite, one expects the presence of surface silanol- and aluminol groups whereas our results can be interpreted with one type of surface $\mathrm{OH}$ groups. This can be explained either as 1) presence of $\mathrm{OH}$ groups with intermediate acid/base characteristics at the montmorillonite surface or 2) that 

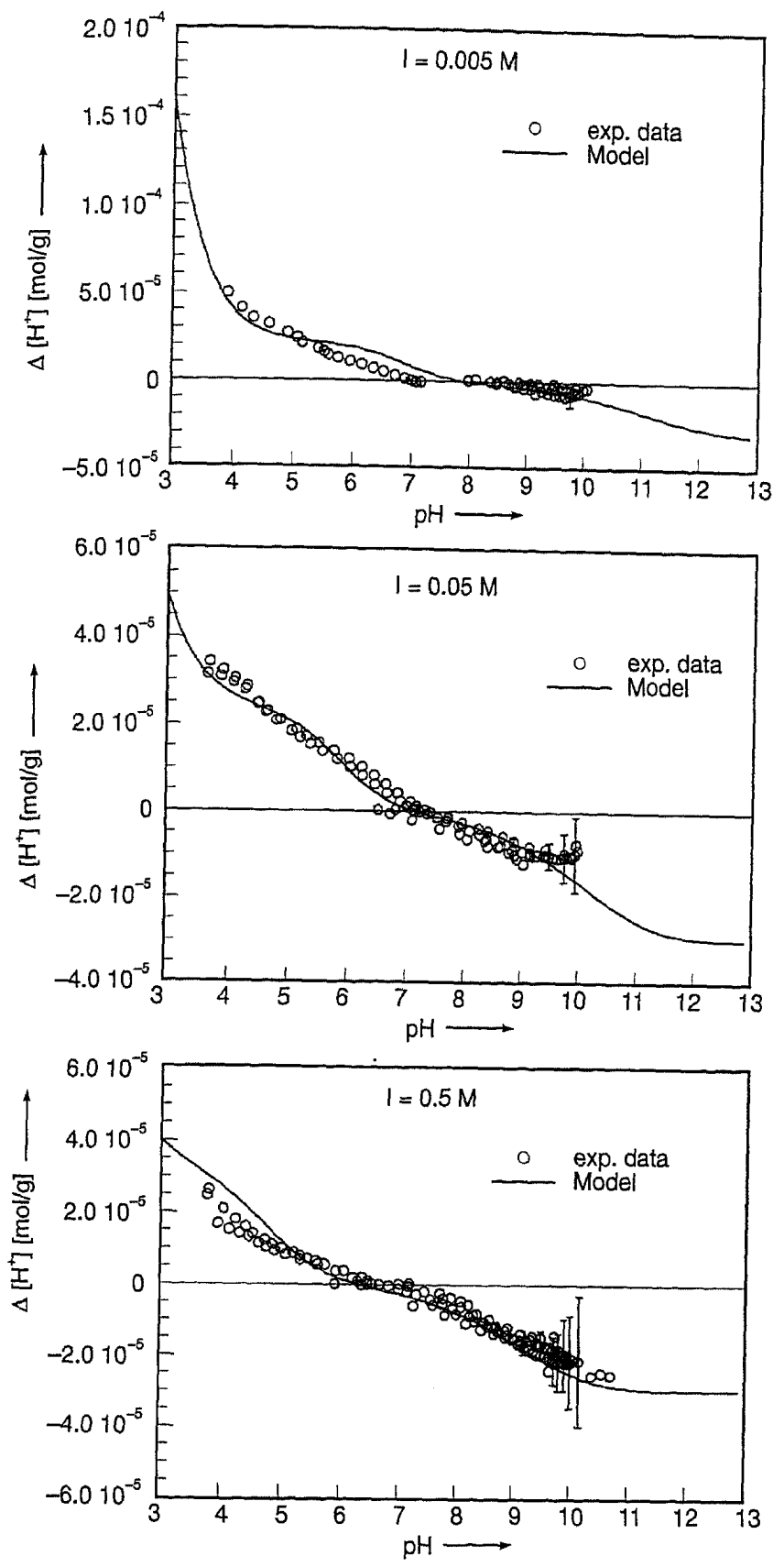

Fig. 3. Simulation of the titration curves of Na-montmorillonite $\left(I=0.005,0.05\right.$ and $0.5 \mathrm{~mol} / \mathrm{dm}^{3} \mathrm{NaNO}_{3}$, montmorillonite $=$ $5 \mathrm{~g} / \mathrm{dm}^{3}$ ). Model computations (solid lines) were performed using the reactions and model parameters listed in Table 2.

$\mathrm{Al}$ (III) are adsorbed onto silanol groups and, hence, the functional surface sites are $\equiv \mathrm{Al}(\mathrm{OH}) \mathrm{OH}_{2}$ groups.

The total number of structural-charge sites which are accessible for $\mathrm{Na} / \mathrm{H}$ exchange reactions under the given experimental conditions amounts to $2.2 \times 10^{-5}$ $\mathrm{mol} / \mathrm{g}(2.2 \mathrm{meq} / 100 \mathrm{~g})$. This value corresponds to about $2 \%$ of the total CEC (CEC $=108 \mathrm{meq} / 100 \mathrm{~g}$ ). We interprete this results as follows: Only a small fraction of layer sites are in equilibrium with the aqueous solution during the potentiometric titration of montmorillonite as conducted in this study. This is most likely a kinetic constraint imposed by limiting the equilibration time of our experiments to $10 \mathrm{~min}$. A longer equilibration time would probably increase the fraction of structural-charge sites accessible for $\mathrm{Na} / \mathrm{H}$ exchange reactions. The fraction of surface sites reactive in our experiments is presumably attributable to structural-charge surface sites exposed at the external planes. The thermodynamic constant for the $\mathrm{Na} / \mathrm{H}$ exchange is determined to be $\log K_{X}^{\circ}=4.6$ and indicates a strong affinity of the external layer sites for protons. The total number of surface sites, i.e., the number of variable-charge sites plus structural-charge sites, amounts to $5 \times 10^{-5} \mathrm{~mol} / \mathrm{g}$. This value is comparable with surface site densities of montmorillonite obtained from potentiometric titrations as reported by Zysset (1992), Stadler and Schindler (1993) and Charlet et al. (1993). Note also that the surface chemical model for montmorillonite presented in this study is consistent with the qualitative model proposed for illitic clay minerals by Beene et al. (1991).

The validity of the proposed model can be evaluated by predicting the total proton density at the montmorillonite surface, i.e., $\Delta\left[\mathrm{H}^{+}\right]$, as function of $\mathrm{pH}$ for $I=0.005 \mathrm{M}$ and $I=0.5 \mathrm{M}$ using the modelling parameters listed in Table 2. Model predictions (solid lines) and experimental data are compared for ionic strengths $I=0.005 \mathrm{M}, I=0.5 \mathrm{M}$ and again for $I=$ $0.05 \mathrm{M}$ (see also Figure 2). For all ionic strengths, model prediction and experimental results agree well in the alkaline $\mathrm{pH}$ range where surface $\mathrm{OH}$ groups are the only charge-determining surface sites. The total proton density, $\Delta\left[\mathrm{H}^{+}\right]$, measured in this $\mathrm{pH}$ range is controlled by the deprotonation of $\mathrm{OH}$ groups. Agreement between experimental results and model computation is less accurate but still satisfactory in the acid $\mathrm{pH}$ range. At $\mathrm{pH}<7$, both surface $\mathrm{OH}$ groups and layer sites contribute to the surface proton density, $\Delta\left[\mathrm{H}^{+}\right]$. Figure 3 shows that the proposed surface chemical model adequately describes the pH-dependent protonation of the montmorillonite surface in the range $I=0.005 \mathrm{M}$ to $0.5 \mathrm{M}$.

\section{Acknowledgments}

We are indebted to Stellan Holgersson for carrying out the titrations. Financial support by the Swedish Nuclear Fuel and Waste Management Co. (SKB) is gratefully acknowledged.

\section{References}

Anderson, S. J., Sposito, G.: Cesium-adsorption method for measuring accessible structural surface charge. Soil. Sci. Soc. Am. J. 55, 1569-1576 (1991).

Beene, G. M., Bryant, R., Williams, D. J. A.: Electrochemical properties of illites. J. Coll. Int. Sci. 147, 358-369 (1991).

Charlet, L., Schindler, P. W., Spadini, L., Furrer, G., Zysset, M.: Cation adsorption on oxides and clays: The aluminium case. Aquat. Sci. 55, 291-303 (1993).

Dzombak, D. A., Morel, F. M. M.: Surface complexation modelling: Hydrous ferric oxides. New York: John Wiley (1990).

Fletcher, P., Sposito, G.: The chemical modelling of clay/electrolyte interactions for montmorillonite. Clay Miner. 24, 375391 (1989).

Huang, C. P., Stumm, W.: Specific adsorption of cations on hy- drous $\gamma-\mathrm{Al}_{2} \mathrm{O}_{3}$. J. Coll. Int. Sci. 43, 409-420 (1973). 
James, R. O., Parks, G. A.: Characterization of aqueous colloids by their electrical double-layer and intrinsic surface chemical properties. Surf. Coll. Sci. 12, 119-216 (1982).

Ludwig, Ch.: GRFIT - a programm for solving speciation problems, Chemistry Department, University of Bern, Bern, Switzerland. (1992).

Sposito, G., Holtzclaw, K. M., Johnston, C. T., Le Vesque, C. S.: Thermodynamics of sodium-copper exchange on Wyoming bentonite at 298 K. Soil. Sci. Soc. Am. J. 43, 47-51 (1981).

Sposito, G.: The surface chemistry of soils. New York: Oxford University Press. (1984).

Stadler, M., Schindler, P. W.: Modeling of $\mathrm{H}^{+}$and $\mathrm{Cu}^{2+}$ adsorption on calcium-montmorillonite. Clays and Clay Miner. 41, 288-296 (1993).

Stumm, W., Huang, C. P., Jenkins, S. R.: Specific chemical interactions affecting the stability of dispersed systems. Croat. Chim. Acta 42, 223-244 (1970).
Stumm, W., Morgan, J. J.: Aquatic chemistry. New York: John Wiley (1981).

Wanner, H., Wersin, P., Sierro, N.: Thermodynamic modelling of bentonite-ground water interaction and implications for near field chemistry in a repository for spent fuel. SKB TR 92-37, Swedish Nuclear Fuel and Waste Management Co., Stockholm, Sweden (1992).

Westall, J. C.: FITEQL: A programm for the determination of chemical equilibrium constants from experimental data. Technical report, Chemistry Departement, Oregon State University, Corvallis, Oregon, USA (1982).

Wieland, E., Stumm, W.: Dissolution kinetics of kaolinite in acidic aqueous solutions at $25^{\circ} \mathrm{C}$. Geochim. Cosmochim. Acta 56, 3339-3355 (1992).

Zysset, M.: Die protoneninduzierte Auflösung von K-Montmorillonit. Ph. D. Thesis. Bern University, Bern, Switzerland. (1992). 